\title{
SHOCK COMPRESSION OF QUARTZ AND ALUMINUM POWDER MIXTURES
}

\author{
V. S. Joshi", N. N. Thadhani ${ }^{\star *}$, R. A. Graham ${ }^{\star \star *}$ and G. T. Holman Jr. ${ }^{\star \star *}$ \\ "Energetic Materials Research and Testing Center, New Mexico Tech, Socorro, NM 87801, USA \\ "School of Materials Science and Engineering, Georgia Institute of Technology, Atlanta, GA 30332, USA \\ ***Advanced Materials Physics and Devices, Sandia National Laboratories, Albuquerque, NM 87185, USA
}

\begin{abstract}
We report about the shock-compression response of highly porous ( $55 \%$ and $65 \%$ dense) mixtures of $4 \mathrm{Al}$ $+3 \mathrm{SiO}_{2}$ powders having shock-induced phase transitions and chemical reactions. Shock recovery experiments were performed using the CETR/Sawaoka plate-impact system ( $\mathrm{P}=40$ to $100 \mathrm{GPa}$ ) and the Sandia Momma Bear A Comp B fixture ( $\mathrm{P}=22$ to $45 \mathrm{GPa})$. The recovered compacts contained the high pressure stishovite phase, products of chemical reaction, as well as unreacted constituents. The reaction products formed included $\mathrm{Al}_{2} \mathrm{O}_{3}$, metallic $\mathrm{Si}$ (ambient and high pressure phases), SiAl intermetallic, and kyanite $\left(\mathrm{Al}_{2} \mathrm{SiO}_{5}\right)$. The shock-induced chemical reaction in $4 \mathrm{Al}+3 \mathrm{SiO}_{2}$ powder mixtures, appears to have been accompanied (or assisted) by the formation of stishovite, a high pressure phase of quartz.
\end{abstract}

\section{INTRODUCTION}

Polymorphic transitions in quartz have been studied both by static (1-2) as well as by dynamic high pressure methods (3-5), as have also been reviewed by Duvall and Graham (6). The continued interest in phase transformation of quartz has been partly due to lack of understanding of the mechanisms governing its behavior under shock-wave loading. Similarly, shock-induced chemical reactions(7-9), initiated in powder mixtures during propagation of shock waves, are also being studied to understand the reaction mechanisms. Aluminum+quartz mixture is of interest and is one of the weakly exothermic $\left(\Delta \mathrm{H}_{R}=-6.2\right.$ $\mathrm{kJ} / \mathrm{cal}$ ) metal/ metal-oxide (thermite) system.

Podurets and coworkers (10) have reported about shock-induced phase transformation of quartz to stishovite in mixtures of $\mathrm{Al}+\mathrm{SiO}_{2}$ in 50:50, 60:40 and 70:30 weight proportions. The starting material had virtually no porosity, thus, the probability of a chemical reaction was minimized. Various other studies by Chao et al. (2), Wackerle (4) and McQueen et al.(5) have demonstrated that the stishovite phase is relatively stable at room temperature, and once formed can be retained. Podurets and coworkers (10) observed stishovite formation in their mixtures at pressures significantly lower than those reported by other investigators (2-5), attributing it to the increase in pressures caused by local impedance mismatch between $\mathrm{Al}$ and $\mathrm{SiO}_{2}$.

Shock-induced chemical reactions have been extensively investigated in different metal/ metaloxide and metal/metal powder mixtures. Mixture of Aluminum and quartz represents an interesting materials system which can not only undergo chemical reactions, but also have transformation of the starting quartz material as well as of the metallic Si material (product of reaction). Thus, the objective of the research presented here was to examine the behavior of the $55 \%$ and $65 \%$ dense $4 \mathrm{Al}+3 \mathrm{SiO}_{2}$ powder mixtures under shock-compression.

\section{EXPERIMENTAL}

Shock recovery experiments were performed over a range of shock pressures using the well designed and calibrated 12-capsule CETR-Sawaoka system for high shock pressures (60-100 $\mathrm{GPa}$ ) at two different velocities $(1.9 \mathrm{~km} / \mathrm{s}$ and $1.1 \mathrm{~km} / \mathrm{s})$, a modified $12-$ capsule system using the CETR-Holman capsule for moderate shock pressures $(40-60 \mathrm{GPa}$ ) at a velocity of $1.1 \mathrm{~km} / \mathrm{s}$, and the Sandia Momma Bear A Comp B 
fixture for low pressure (22-46 GPa) experiments, using a driver plate arrangement. Details of each of these shock recovery fixtures and the corresponding two-dimensional numerical simulations have been discussed and documented elsewhere (11).

Pure aluminum powder obtained from ALCOA and quartz powder obtained from CERAC was blended in the ratio of $4: 3$ (stoichiometric ratio to obtain complete reaction) in a ball mill under an argon atmosphere for 8-12 hours. A characteristic scanning electron micrograph of the powder mixture is shown in Fig.1. Aluminum powder was relatively coarse ( 44 microns) and appeared more rounded than the quartz powder.

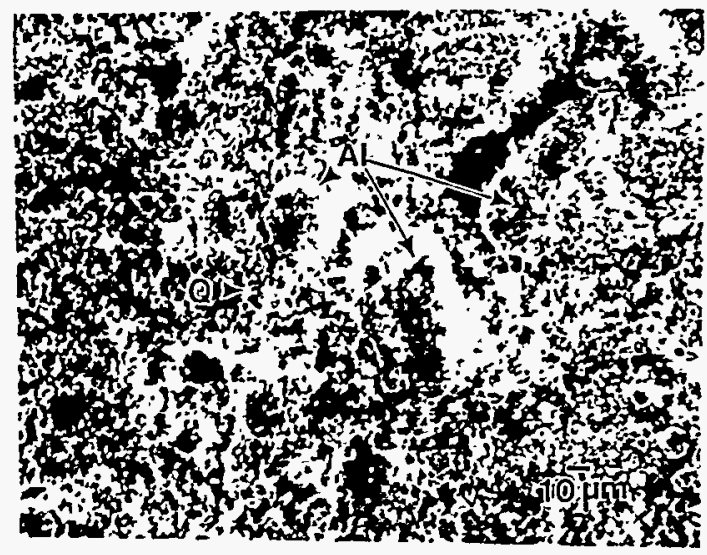

FIGURE 1. Scanning Electron Microscope image of the starting powder mixture, showing aluminum $(\mathrm{Al})$ and quartz $(\mathrm{Q})$ particles.

The powders were pressed in capsules at the desired packing densities, and sealed in the respective holding fixtures. Table 1 lists the type and characteristics of powders, their packing densities, and other details of experimental conditions.

\section{RESULTS AND DISCUSSIONS}

Optical and scanning electron microscopy observations as well as $\mathrm{x}$-ray diffraction analysis were conducted on the longitudinal cross-sections of the recovered shocked compacts. A low magnification optical microscopy analysis of the longitudinal crosssectional surfaces, revealed extensive reaction in the compacts of the high velocity Sawaoka experiment (\#9404-03), partial reaction in localized areas in the low velocity Sawaoka (\#9022-12) and Holman (\#9028-09) capsule experiments, and no reaction in the low pressure (Momma Bear) compact. A typical optical micrograph of the cross-sections of compact, revealing partial reaction is shown in Fig. 2. The central (axial) region towards the bottom (non-impact side) of the compact has a different contrast compared to the bulk of the compact, indicating the possibility of reaction in regions dominated by radial shock-wave focussing effects.

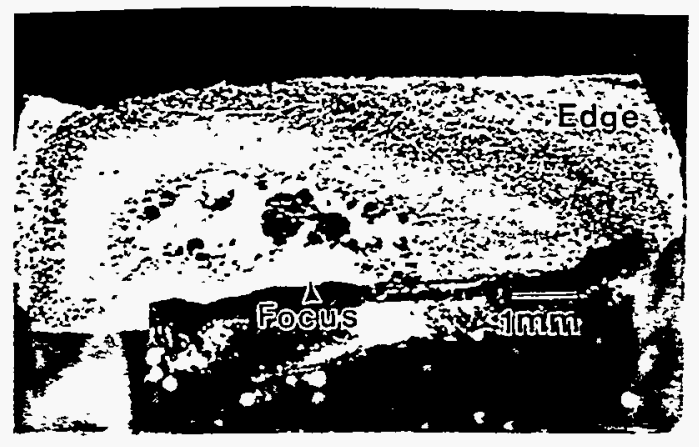

FIGURE 2. Optical Microscope image of the cross-section of the compact \#9022-12, indicating different extent of reaction in various regions.

Detailed analysis of these regions at higher

TABLE 1. Experimental Conditions and Powder Characteristics.

\begin{tabular}{lcllll}
\hline Sample No. & Mix No.* & Fixture & Impact velocity & Packing Density & Peak Pressures \\
\hline $9022-12$ & SNL 0790-2 & Sawaoka & $1.10 \mathrm{~km} / \mathrm{s}$ & $1.53 \mathrm{gm} / \mathrm{cc}(57.4 \%)$ & $60-100 \mathrm{GPa}$ \\
$9028-09$ & $"$ & Holman & $1.16 \mathrm{~km} / \mathrm{s}$ & $1.51 \mathrm{gm} / \mathrm{cc}(56.4 \%)$ & $40-60 \mathrm{GPa}$ \\
$9404-03$ & $"$ & Sawaoka & $1.90 \mathrm{~km} / \mathrm{s}$ & $1.81 \mathrm{gm} / \mathrm{cc}(66.9 \%)$ & $100 \mathrm{GPa}$ \\
$94 \mathrm{~B}-12$ & $"$ & Sandia & $\mathrm{MBA}-\mathrm{CB}$ & $1.48 \mathrm{gm} / \mathrm{cc}(55.1 \%)$ & $22-46 \mathrm{GPa}$ \\
\hline
\end{tabular}

* $\mathrm{SiO}_{2}$ - CERAC S-1061, Lot\# 10542, -325 mesh, 99.9\%, Al - ALCOA 56251, Lot\# 3336-21, -325 mesh, 90.6\% 
magnification, revealed that extensive reaction had occurred. Typical reaction areas of sample is shown in Fig. 3. The presence of spherical voids (SV), and shiny contrast of globules of metallic reaction product (MR) is an indication of chemical reactions in the central high pressure regions of the compacts.

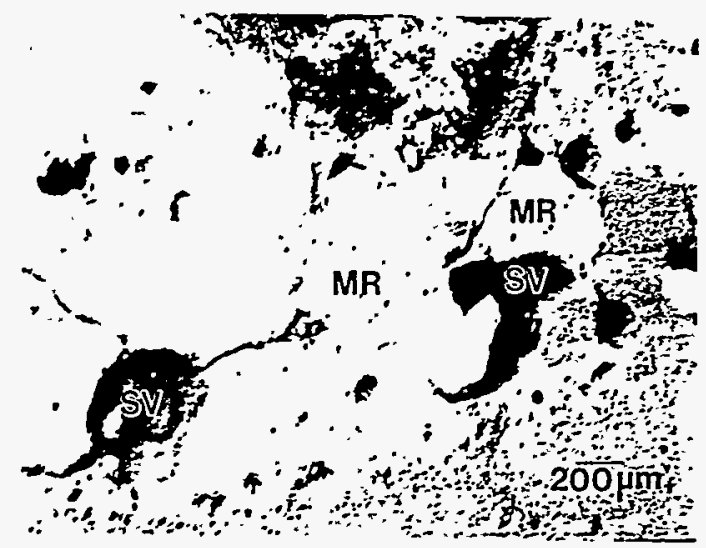

FIGURE 3. Scanning Electron Microscope image of the reacted region of sample 9022-12, showing voids (SV) and metallic reaction product (MR).

In some cases, these metallic globules were found to contain Al-Si intermetallic composition. A typical unreacted region of a compact is shown in Fig. 4, revealing the differential contrast of the starting powder mixtures.

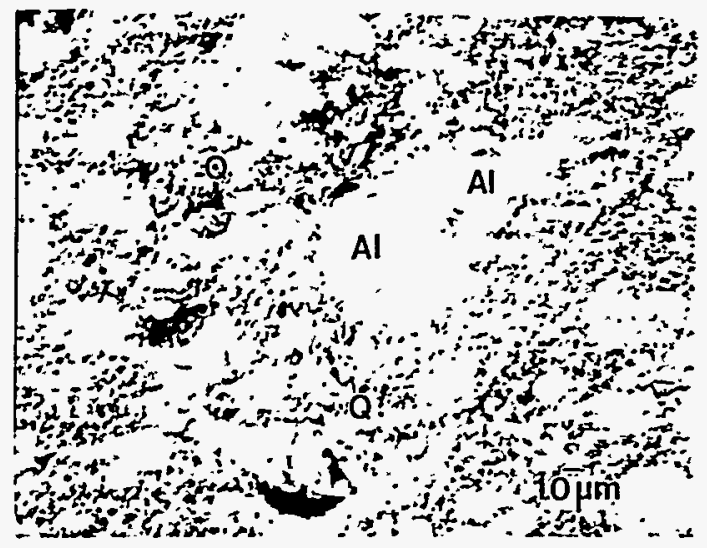

FIGURE 4. Scanning Electron Microscope image of unreacted region of sample \#94B-12, showing original particles of aluminum (Al) and quartz (Q).
$\mathrm{X}$-ray diffraction $(\mathrm{XRD})$ analysis showed peaks for a combination of products of chemical reaction as well as peaks for materials that had undergone phase transformation. The individual XRD plots for the starting powder mixture and each of the four compacts are shown in Fig. 5 (a-e).

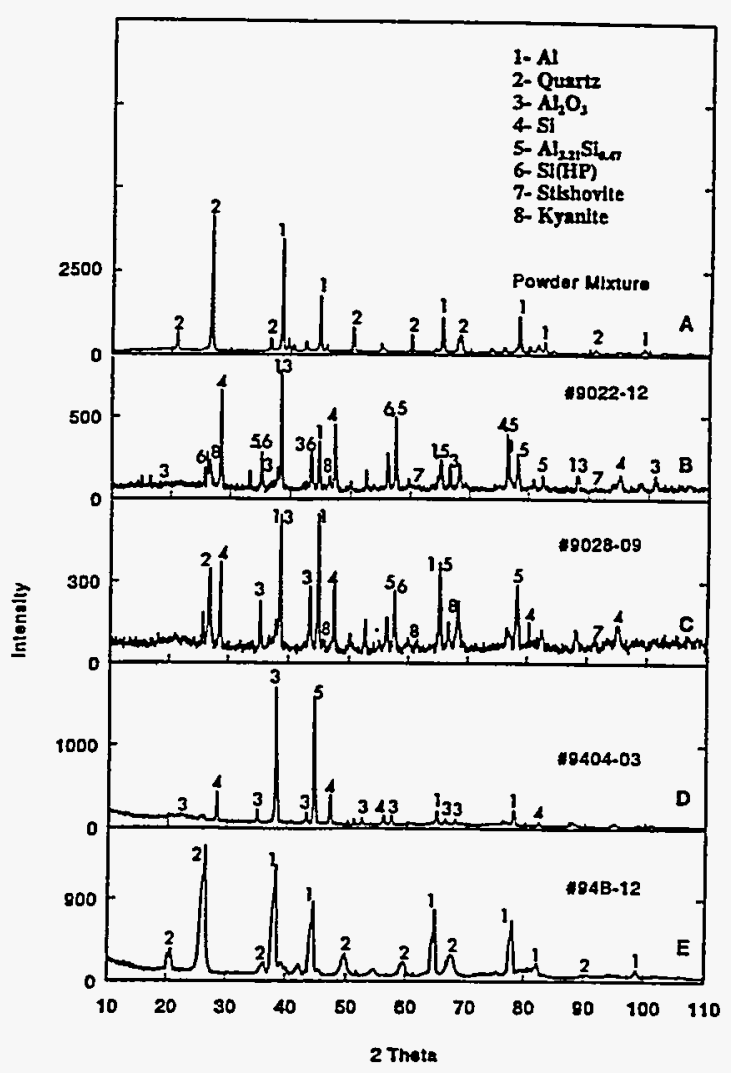

FIGURE 5. X-ray diffraction patterns of starting material and compacts; (a) starting powder mixture, (b) sample \# 9022-12, (c) sample \#9028-09, (d) sample \#9404-03, and (e) sample \#94B-12.

The low pressure MBA-CB sample (\#94B-12) showed predominant peaks of unreacted powders $(\mathrm{Al}$, $\mathrm{SiO}_{2}$ ). The Holman capsule sample (\#9028-09) also showed predominant peaks of unreacted constituents and low-intensity peaks of reaction products such as $\mathrm{Al}_{2} \mathrm{O}_{3}$ (corundum) and $\mathrm{Si}$ metal. Both the MBA-CB (\#94B-12) and Holman sample (\#9028-09) showed shifts in the d-spacings of the majority of the $\mathrm{Al}$ diffraction lines, indicating possibility of extensive strain retention in the shocked material. The Sawaoka 
capsule experiments (samples \#9022-12 and 940403 ), showed prominent peaks of fully reacted material. The lower impact velocity sample (\#9022) showed presence of small proportions of kyanite $\left(\mathrm{Al}_{2} \mathrm{SiO}_{5}\right)$ and $\mathrm{Al}_{3.21} \mathrm{Si}_{0.47}$ intermetallic, in addition to the common products $\mathrm{Al}_{2} \mathrm{O}_{3}$ (corundum) and Si metal. The higher impact velocity sample (9403-03) which underwent complete reaction did not show the kyanite $\left(\mathrm{Al}_{2} \mathrm{SiO}_{5}\right)$ phases. In addition, the high pressure phase of silicon and that of quartz (stishovite), observed in \#9022-12, was not detected in this high impact velocity sample. Surprisingly, coesite, a moderate pressure phase of $\mathrm{SiO}_{2}$ was not detected in any of the shock-compressed samples. The phase transformation of $\mathrm{SiO}_{2}$ (starting material) as well as that of silicon (reaction product), as detected in sample \# 9022-12 suggests that both, the reactant $\mathrm{SiO}_{2}$ and product $\mathrm{Si}$, coexisted in the high-pressure state. The coexistence of one of the reactants and products, both of which undergo transformation to the high pressure phase, indicates that at least part of the chemical reaction has happened during the high pressure shock state. In fact, it may be possible that the high-pressure phase of the reactant, $\mathrm{SiO}_{2}$, generates the configuration necessary for reaction initiation, in an otherwise weakly exothermic system. The absence of XRD peaks of the high pressure phases in the high-impact velocity sample (\#9404-03), where complete reaction had occurred, could be due to the reversal of the high pressure phases due to excessive temperatures, generated as a result of shock-compression as well as exothermic reaction, when the reactants were fully converted to reaction products.

\section{CONCLUSION}

It is shown that highly porous $4 \mathrm{Al}+3 \mathrm{SiO}_{2}$ powder mixtures undergo simultaneous shock-induced chemical reaction and shock-induced phase transformation of both reactant as well as of reaction products. The coexistence of one of the reactants (quartz) in the form of a high pressure phase (stishovite) and the high pressure phase of the reaction product $(\mathrm{Si})$, detected by $\mathrm{x}$-ray diffraction analysis, suggests occurrence of the chemical reaction between $\mathrm{Al}$ and $\mathrm{SiO}_{2}$ during the high pressure shock-loaded state. The observed high pressure phases also suggest that the shock-induced chemical reaction in the weakly exothermic metal $(\mathrm{Al})$ and metal-oxide $\left(\mathrm{SiO}_{2}\right)$ system, follows a path involving the phase transformation of the $\mathrm{SiO}_{2}$ reactant, prior to actual chemical reaction.

\section{ACKNOWLEDGMENTS}

This work was supported by Sandia National Laboratories under grant No. 42-5737, at New Mexico Tech. Extended support was also provided by EMRTC, New Mexico Tech., and in part by NSF Contract No. DMR-936132, at Georgia Tech.

\section{REFERENCES}

1. Stishov, S. M., and Popova, S.V., Geokhimiya 10, 837-839 (1961).

2. Chao, E. C. T., Fahey, J. J., Littler, J., and Milton, D. J., J. Geophys. Res. 67, 419-421 (1962).

3. Adadurov, P. A., Dremin, A. N., Pershin, S. V., Rodionov, V. N., and Ryabinin, Y. N., Zh. Prikl. Mekh. Tekh. Fiz. 2, 81 (1962).

4. Wackerle, J., J. Appl. Phys. 33, $922-934$ (1962).

5. McQueen, R. G., Fritz, J. N., and Marsh, S. P., J. Geoph. Res. 68, 2319-2322 (1963).

6. Duvall, G. E., and Graham, R. A., Rev. Mod. Phys 49, 523-579 (1977).

7. Graham, R. A., Morosin, B., Ventruini, E. L., and Carr, M. J., Ann. Rev. Mater. Sci. 16, 315341 (1986).

8. Dremin, A. N., and Bruesov, O. N., Russian Chemical Reviews 37, 392-402 (1968).

9. Thadhani, N. N., Progress in Materials Science 37, 117-226 (1993).

10. Podurets, M. A., Simakov, G. V., and Trunin, R. F., Izvestiya, Earth Physics 24, 267-270 (1988).

11. Thadhani, N. N., Holman, G. T., Romero, B., and Graham, R. A., "The CETR/Sawaoka 12-Capsule Plate Impact Shock Recovery Fixture: Design and Experimentation," CETR Report A-01-91 (1991). 


\section{DISCLAIMER}

This report was prepared as an account of work sponsored by an agency of the United States Government. Neither the United States Government noi any agency thereof, nor any of their employees, makes any warranty, express or implied, or assumes any legal liability or responsibility for the accuracy, completeness, or usefulness of any information, apparatus, product, or process disclosed, or represents that its use would not infringe privately owned rights. Reference herein to any specific commercial product, process, or service by trade name, trademark, manufac: turer, or otherwise does not necessarily constitute or imply its endorsement, recommendation, or favoring by the United States Governmeat or any agency thereof. The views and opinions of authors expressed herein do not necessarily state or reflect those of the United States Government or any agency thereof. 


\section{DISCLAIMER}

This report was prepared as an account of work sponsored by an agency of the United States Government. Neither the United States Government nor any agency thereof, nor any of their employees, makes any warranty, express or implied, or assumes any legal liability or responsibility for the accuracy, completeness, or usefulness of any information, apparatus, product, or process disclosed, or represents that its use would not infringe privately owned rights. Reference herein to any specific commercial product, process, or service by trade name, trademark, manufacturer, or otherwise does not necessarily constitute or imply its endorsement, recommendation, or favoring by the United States Government or any agency thereof. The views and opinions of authors expressed herein do not necessarily state or reflect those of the United States Government or any agency thereof.

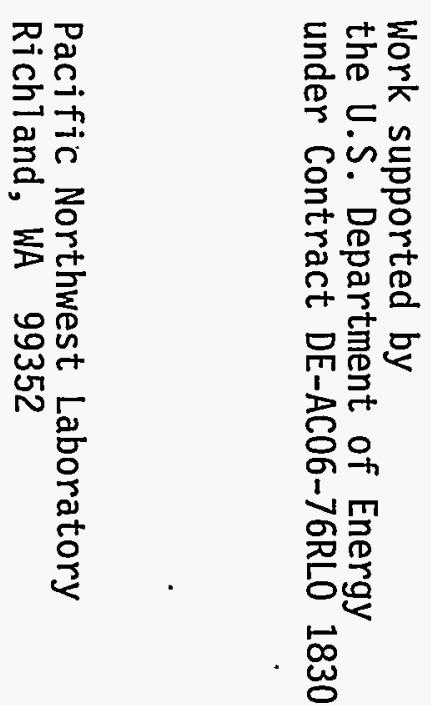
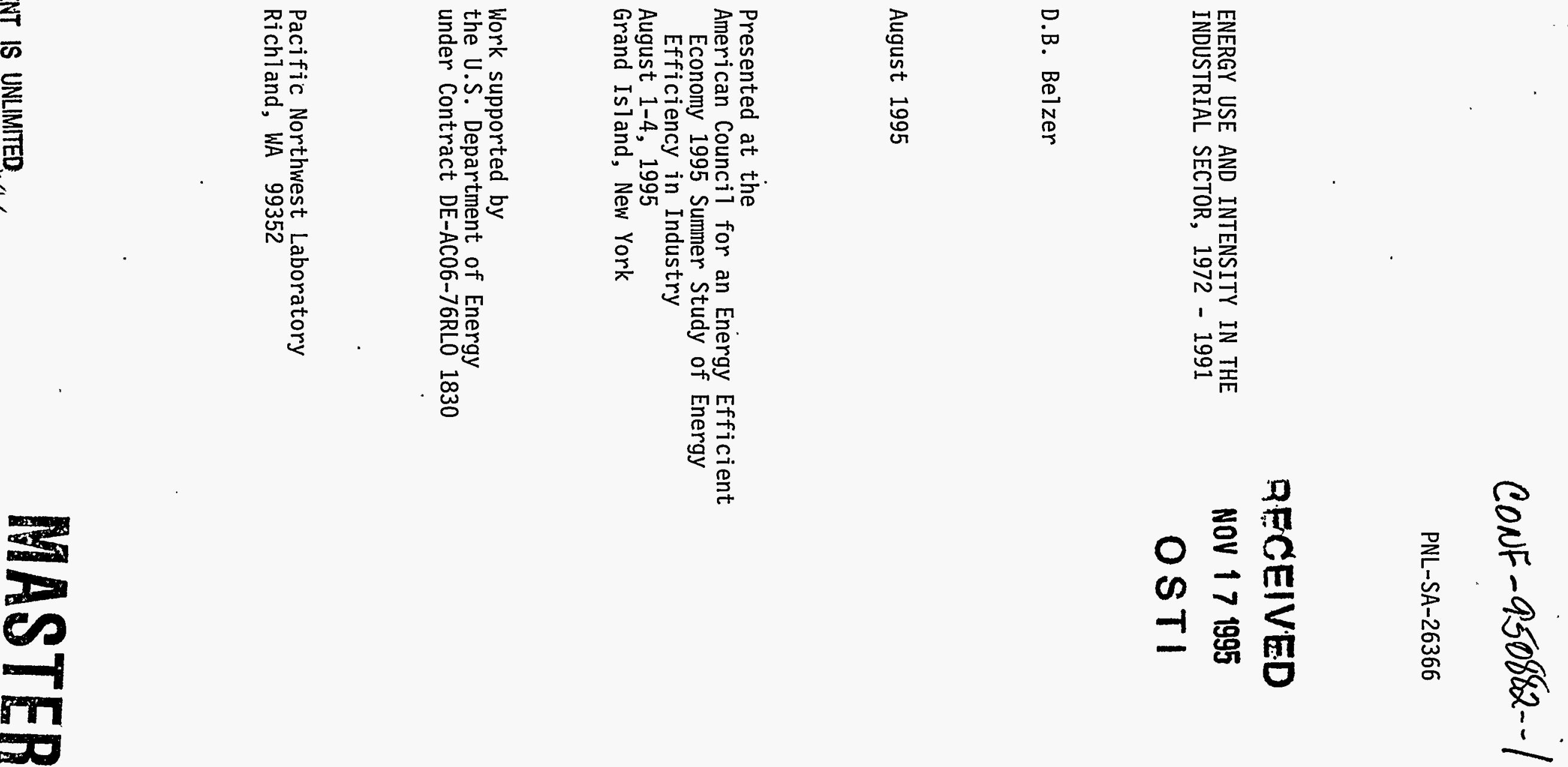


\title{
ENERGY USE AND INTENSITY IN THE INDUSTRIAL SECTOR, 1972-1991
}

\author{
D. B. Belzer, Pacific Northwest Laboratory ${ }^{(a)}$
}

Energy use in the United States is substantially lower now than it would have been had energy intensities not fallen after the oil price shocks of the 1970s. The United States would have consumed over 30 quadrillion Btu (QBtu) more energy in 1991 if the energy-GDP ratio (energy divided by gross domestic product) had remained at its 1972 value. Much of this improvement has stemmed from developments within the industrial sector.

This paper examines industrial energy use from two perspectives. First, the contribution of the industrial sector to the decline in the overall energy-GDP ratio is estimated. Second, the components of change in conservation trends within the industrial sector are examined. This part of the analysis identifies the change in overall industrial intensity (total energy consumption/total industrial output) that is due to improvements in energy intensity at the individual industry level in comparison to various aspects of the composition of industrial output.

This paper is based upon recent work conducted by Pacific Northwest Laboratory for the Office of Energy Efficiency and Alternative Fuels Policy, U.S. Department of Energy. Discussion of other end-use sectors and some additional analysis of industrial sector energy trends is found in Energy Conservation Trends - Understanding the Factors Affecting Conservation Gains and their Implications for Policy Development. ${ }^{(1)}$

\section{CONTRIBUTION OF INDUSTRIAL SECTOR TO DECLINE IN ENERGY-GDP RATIO}

Although the energy-GDP ratio provides a broad indicator of overall energy efficiency in the economy, as many analysts have pointed out, changes in this indicator result from structural changes in the economy as well as from improvements in technical efficiency. Thus, the industrial sector would contribute to a lower energy-GDP ratio if it declined in relation to total GDP, even if its own energy intensity remained constant.

Within a simple multiplicative framework, a Divisia index methodology was used recently to analyze the relative contributions of the major end-use sectors (residential, commercial, industrial, and transportation) to the decline in the overall energy-GDP ratio since 1972. (A brief description of this methodology is given in Reference 1.) Numbering these four end-use sectors in sequence, we can consider the energy-GDP ratio to be the sum of four separate ratios corresponding to each of the sectors:

$$
E / G D P=E_{1} / G D P+E_{2} / G D P+E_{3} / G D P+E_{4} / G D P
$$

Thus, to explain any change in the overall energy-GDP ratio, we need to explain the individual ratios on the right side of Equation (1). Each term on the right of Equation (1) can in turn be expressed as

$$
E_{j} / G D P=E_{j} / A_{j} \times A_{j} / G D P
$$

The $A_{j}$ is an overall activity measure for the sector $j$. The first term on the right side of Equation (2) is simply an aggregate energy-intensity metric for the end-use sector. The following activity measures were chosen to define intensity measures for each sector:

(a) Pacific Northwest Laboratory is operated for the U.S. Department of Energy by Battelle Memorial Institute under Contract DE-ÁC06-76RLO 1830. 


$\begin{array}{ll}\text { Residential } & \text { Number of Households } \\ \text { Commercial } & \text { Total Floorspace } \\ \text { Industrial } & \text { GDP Originating } \\ \text { Transportation } & \text { Passenger-miles } \\ & \text { Freight ton-miles }\end{array}$

A Divisia decomposition is used to generate the contribution of each of the terms in Equation (2) to a change in overall energy-GDP ratio between any two periods. The contribution of the E/A terms is savings due to intensity changes. The contribution of the $A_{j} / G D P$ terms in Equation (2) is considered structural change. Thus, for example, the energy-GDP ratio will fall simply as the ratio of industrial GDP falls relative to total GDP.

Since this procedure is additive, the sum of the structural change and sectoral intensity components across all sectors equals the change in energy-GDP ratio. Taking the changes in this ratio from 1972 for this study, we compute the level of energy savings in Btu after multiplying by total GDP. Thus, this approach provides a convenient method of decomposing aggregate savings by end-use sector.

Figure 1 shows several key components that have contributed to the decline in the energy-GDP ratio over the 1972-1991 period. The energy-GDP ratio fell from $22.9 \mathrm{kBtu} / 1987 \$$ in 1972 to $16.7 \mathrm{kBtu} / 1987 \$$ in 1991 . The topmost area on the plot shows the net contribution of the structural factors as described above. They are responsible for about 43 percent of the total drop. (This magnitude also includes the effect of increasing electrification in the economy-discussed separately below). The middle area shows the contribution of the (delivered) energyintensity decline in the industrial sector, nearly 32 percent of the overall decline. The lowest area shows the contribution of the other end-use sectors. Together they account for about 25 percent of the drop in E/GDP over the 20-year period.

Figure 1. Change in Energy-GDP Ratio, 1972-1991: Major Factors

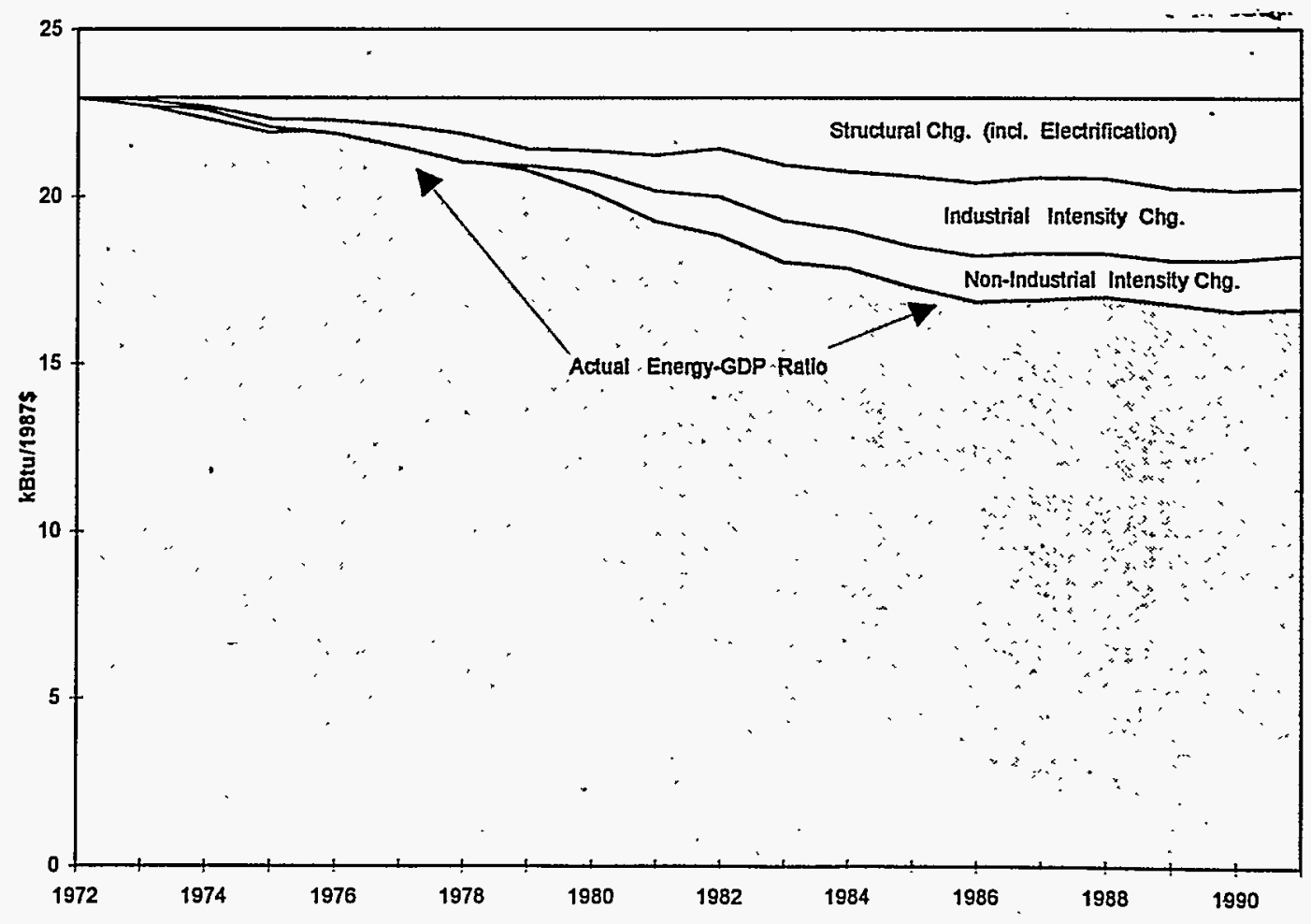


Figure 2 shows a breakdown of the total 1991 economy-wide energy savings of 30.6 QBtu since 1972, based upon the decline in energy-GDP ratio. Consistent with Figure 1, the largest single contribution is 9.7 QBtu of savings attributable to the decline in the delivered energy intensity in the industrial sector. Savings from the decline in residential energy (delivered) energy intensity contributed about $5 \mathrm{QBtu}$ over the same period. Both of the building sectors show the largest negative components associated with increased electricity consumption. Electrification has not been nearly as important in the industrial sector.

The structural factors in Figure 2 relate strictly to the trends in the various activity measures in the end-use sectors in relation to total GDP. While all of the activity measures fall relative to GDP, the decline in industrial GDP to total GDP accounts for the largest structural component of energy savings.

\section{DECOMPOSITION OF INDUSTRIAL ENERGY INTENSITY: APPROACH}

This section takes a more detailed look at what has influenced the decline in overall delivered energy intensity of the industrial sector. The approach to analyzing changes in the overall industrial energy intensity generally follows that outlined by Boyd et al. ${ }^{(2)}$ in focusing upon two components behind the trends in industrial consumption. The first component involves changes in energy intensity-energy consumption per unit of output-by specific industrial sector. The second component involves changes in the composition of industrial output. The predominant aspect of this component has been a shift away from the major energy-intensive sectors (e.g., primary metals) and a shift toward lighter manufacturing activities.

Figure 2. Comparison of Primary Energy Savings Contributions by End-Use Sector, 1991

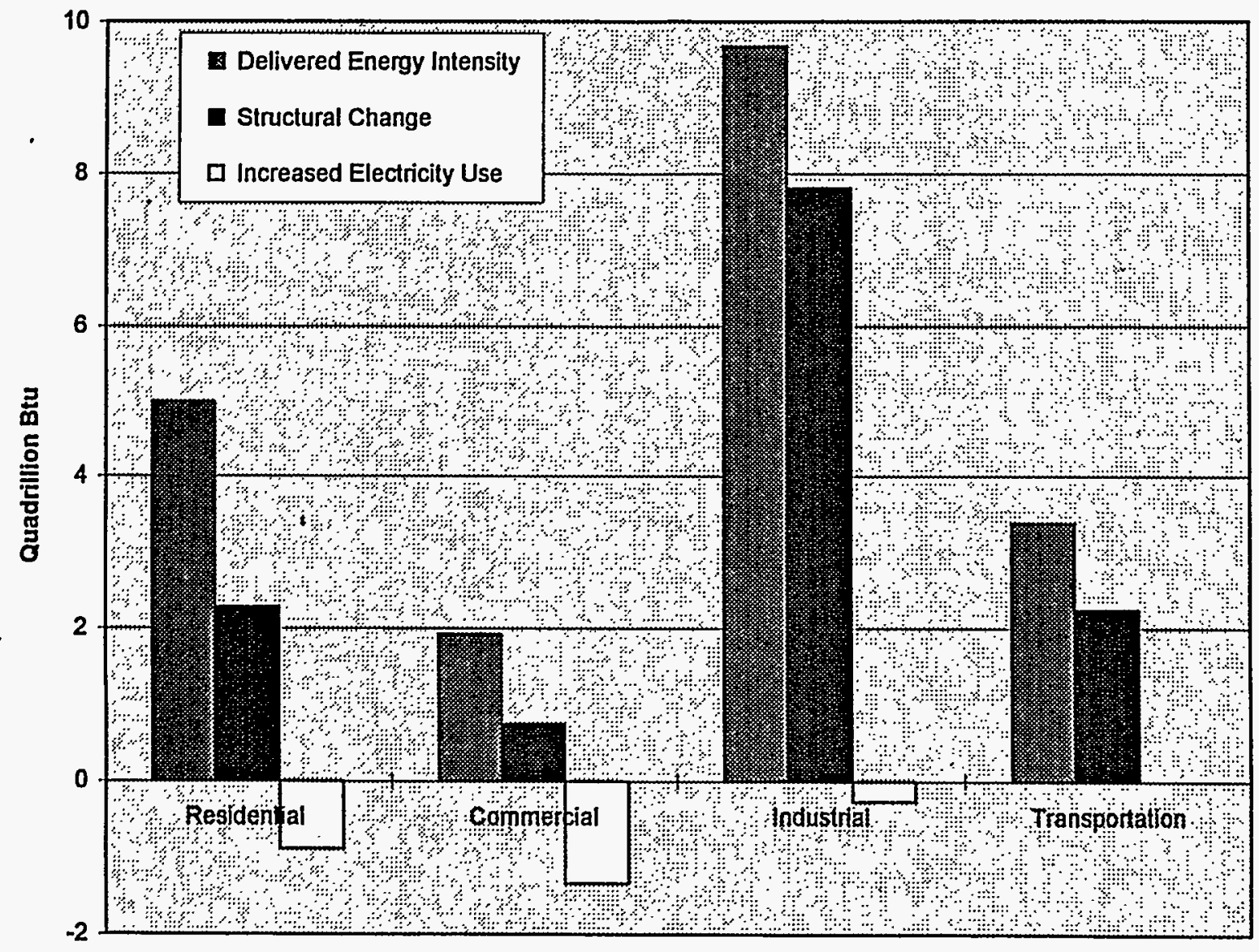


This work extends the analysis of Boyd et al. in several ways. ${ }^{(2)}$ First, this study broadens the -scope of the analysis to include agriculture, mining, and construction. This broader scope is more consistent with the total industrial energy consumption information published by the Energy Information Administration. ${ }^{(3)}$ The study also provides a more in-depth look at the sensitivity of the results to various measures of output.

Second, the study distinguishes energy used for heat and power from the energy used as material inputs to production. The most important energy material inputs involve asphalt (linked to the construction sector), petrochemical feedstocks, coke, and fuel oil. The sum of heat and power and material inputs is calibrated to match the total industrial consumption as published by EIA. A brief discussion of the energy and output data construction methods are given in the Appendix.

\section{Analytical Method}

Several methodological decisions must be made in order to decompose total changes in consumption into intensity and structural components. As Boyd, Hanson, and Sterner point out, there is no unique method to summarize the process of simultaneous changes in both energy intensity and output levels for various sectors. ${ }^{(4)}$ The approach of Boyd and his coauthors was to use a Divisia index technique to quantify the compositional and intensity components. ${ }^{(2,4)}$ This approach has an important advantage in not requiring the choice of particular time period from which to base the analysis. Moreover, the approach eliminates "interaction effects" among multiplicative factors, which are often difficult to interpret. (Some discussion of this method in given in Reference 1.)

\section{Levels of Disaggregation}

This study used a hierarchical disaggregation approach similar to that employed by Boyd. ${ }^{(2)}$ The top level of the hierarchy is the total industrial sector, as measured by GDP originating in agriculture, mining, construction, and manufacturing. The second level separates manufacturing from nonmanufacturing. In 1991, manufacturing made up about 70 percent of industrial GDP and used over 80 percent of industrial primary energy.

The third level is defined only in manufacturing. Following Boyd et al., the five most energy-intensive two-digit standard industrial classification (SIC) sectors are broken out from the rest of manufacturing. These industries are paper and allied products (SIC 26); chemicals and allied products (SIC 28); petroleum refining (SIC 29); stone, clay, and glass (SIC 32); and primary metals (SIC 33). In 1986, these five industries accounted for 22 percent of manufacturing GDP, but over 60 percent of primary energy consumption.

The fourth level of disaggregation is generally at the two-digit SIC level. Manufacturing comprises 20 two-digit sectors: five in the energy-intensive group and fifteen elsewhere. The breakdown in nonmanufacturing follows the industry detail for GDP by industry as published in the Survey of Current Business.

The fifth level of disaggregation is used to bridge alternative measures of industrial output. At the higher levels of aggregation, GDP is the output measure of choice. At the lowest level (approximately three-digit SIC) the only available output measures are defined in terms of deflated value of gross production, as produced by the Bureau of Labor Statistics (BLS). To bridge between these measures, the BLS gross output measures were aggregated to the two-digit SIC level (corresponding to level 4 above) using value-added weights. The ratio of this value-added weighted production measure to the official GDP estimate at the two-digit SIC level reflects a variety of structural factors. For example, in a single industry, any trend toward more purchased services would tend to increase this ratio, as the ratio of direct labor payments to the value of production would fall. The ratios also incorporate differences in underlying data sources and estimation methodologies.

The sixth level of disaggregation is generally based upon the three-digit SIC sectors generated by the BLS, as discussed above. In the energy-intensive group, this level of disaggregation is useful since it helps to focus on those particularly energy-intensive sub-sectors below the two-digit SIC level. For instance, the primary pulp and paper 
industry is significantly more energy intensive than the other paper industries that simply convert paper products. Within the 5 two-digit energy-intensive sectors, there are 22 sectors at this final level. For the 15 two-digit sectors in the nonenergy-intensive group, 46 sectors are included in the analysis.

\section{DECOMPOSITION RESULTS}

Annual changes in energy consumption were decomposed into an intensity component and components related to structural shifts among sectors (including the definitional adjustment between gross output and real GDP). The Divisia method is especially useful for decomposing any change in a measure expressed as a product of terms-in this application, terms involving energy intensity at a detailed industry level and changes in the relative shares of various output measures over time. The decomposition was carried out separately for fuels used for heat and power and fuels used for materials. This section describes the results of the analysis using only the constant-dollar production measures that were defined through the sixth level of disaggregation discussed above.

\section{Components of the Decomposition}

Using the format and nomenclature used by Boyd et al., ${ }^{(2)}$ we can formally define the components of the analysis as

- Real Energy Intensity - The change in aggregate industrial sector energy intensity that is due only to changes in intensities at the most detailed sectoral level. In this section, this component applies to the energy intensity per dollar of gross output. These components were summed over the 75 BLS sectors. Using the Divisia methodology, a change in energy intensity over a small time interval is translated into a change in the aggregate industrial intensity by multiplying the intensity change by the current output share.

- Structural and Definitional Shifts - The change in aggregate intensity that is attributable to the entire set of structural shifts and the bridging of output definitions. The specific components in this general category are

$S_{1}$ : change in aggregate intensity due solely to the shift between manufacturing and nonmanufacturing sectors (labeled as manufacturing-nonmanufacturing shift)

$\mathrm{S}_{2}$ : change in aggregate intensity due to the shift within manufacturing between the energy-intensive group and the nonenergy-intensive group (following Boyd et al., to be referred to as the intergroup shift)

$S_{3}$ : change in aggregate intensity due the shift of GDP within the energy-intensive manufacturing, nonenergyintensive manufacturing, or nonmanufacturing sectors (referred to as two-digit shift).

$\mathrm{S}_{4}$ : change in aggregate intensity due to changes in ratios of weighted gross production (BLS) to real GDP (Department of Commerce) at the two-digit SIC level (referred to as output definitional change).

$\mathrm{S}_{5}$ : change in aggregate intensity due to shift of BLS-defined sectors within two-digit SIC industries (referred to as within two-digit shift).

\section{Results for Fuels Used for Heat and Power}

Table 1 provides some of the key data used in the decomposition of industrial fuel consumption. As shown in column three, fuel consumption for heat and power in the industrial sector fell from $21.0 \mathrm{QBtu}$ (quadrillion Btu) in 1972 to 18.4 QBtu in 1991, according to the estimates based on the National Energy Accounts database and. adjusted to the EIA published energy consumption for the industrial sector. At the same time, industrial GDP grew by over 30 percent. The resulting overall intensity fell 33 percent as shown in column four. 
Table 1. Industrial Output and Energy Consumption

\begin{tabular}{|c|c|c|c|c|c|c|c|}
\hline \multirow[b]{2}{*}{ Year } & \multirow[b]{2}{*}{$\begin{array}{c}\text { Industrial GDP } \\
\text { (Billion 87\$) }\end{array}$} & \multicolumn{2}{|c|}{ Heat and Power } & \multicolumn{2}{|c|}{ Energy Materials } & \multirow[b]{2}{*}{$\begin{array}{l}\text { Manufac/ } \\
\text { Industrial } \\
\text { (Percent) }\end{array}$} & \multirow[b]{2}{*}{$\begin{array}{l}\text { E-intensiv } \\
\text { Manufac. } \\
\text { (Percent) }\end{array}$} \\
\hline & & $\begin{array}{c}\text { Energy } \\
\text { Consumption } \\
\text { (QBTu) }\end{array}$ & $\begin{array}{c}\text { Energy } \\
\text { Intensity } \\
\mathrm{kBtu} / 87 \$\end{array}$ & $\begin{array}{c}\text { Energy } \\
\text { Consumption } \\
\text { (QBtu) }\end{array}$ & $\begin{array}{c}\text { Energy } \\
\text { Intensity } \\
\mathrm{kBtu} / 87 \$\end{array}$ & & \\
\hline 1972 & 989.5 & 20.994 & 21.22 & 3.612 & 3.65 & 65.3 & 27.5 \\
\hline 1973 & $1,062.4$ & 22.065 & 20.77 & 3.901 & 3.67 & 67.3 & 28.2 \\
\hline$\overline{1974}$ & 1016.3 & 20.846 & 20.51 & 4.151 & 4.08 & 67.0 & 28.5 \\
\hline 1975 & 950.8 & 19.064 & 20.05 & 3.704 & 3.90 & 66.3 & 26.7 \\
\hline 1976 & $1,020.6$ & 20.223 & 19.81 & 3.842 & 3.76 & 67.8 & 27.1 \\
\hline 1977 & $1,080.4$ & 20.525 & 19.00 & 4.108 & 3.80 & 68.7 & 26.7 \\
\hline 1978 & $1,117.2$ & 20.395 & 18.26 & 4.294 & 3.84 & 69.3 & 26.2 \\
\hline 1979 & $1,112.4$ & 21.154 & 19.02 & 4.549 & 4.09 & 69.9 & 25.6 \\
\hline 1980 & $1,055.0$ & 19.565 & 18.55 & 4.305 & 4.08 & 68.9 & 24.1 \\
\hline 1981 & $1,069.3$ & 18.663 & 17.45 & 3.886 & 3.63 & 69.9 & 25.0 \\
\hline 1982 & $1,023.2$ & 16.740 & 16.36 & 3.297 & 3.22 & 69.6 & 23.7 \\
\hline 1983 & $1,044.0$ & 16.057 & 15.38 & 3.347 & 3.21 & 70.3 & 24.2 \\
\hline 1984 & $1,137.0$ & 17.541 & 15.43 & 3.662 & 3.22 & 69.7 & 23.1 \\
\hline 1985 & $1,186.1$ & 16.935 & 14.28 & 3.621 & 3.05 & 68.5 & 22.8 \\
\hline 1986 & $1,196.9$ & 16.349 & 13.66 & 3.784 & 3.16 & 68.5 & 23.7 \\
\hline 1987 & $1,262.3$ & 17.150 & 13.59 & 3.982 & 3.15 & 69.5 & 23.6 \\
\hline 1988 & $1,314.7$ & 18.092 & 13.76 & 4.022 & 3.06 & 70.3 & 22.9 \\
\hline 1989 & $1,316.4$ & 18.288 & 13.89 & 3.987 & 3.03 & 70.8 & 22.9 \\
\hline 1990 & $1,326.3$ & 18.635 & 14.050 & 4.220 & 3.18 & 70.0 & 23.3 \\
\hline 1991 & $1,296.3$ & 18.434 & 14.22 & 4.133 & 3.19 & 70.3 & 23.5 \\
\hline
\end{tabular}

Columns seven and eight of Table 1 show two of the key compositional trends that lie behind the change in overall industrial intensity. Column seven is the fraction of total industrial GDP contributed by manufacturing. The manufacturing share grew steadily during the 1970s, but has remained a fairly constant share of industrial GDP since 1982. Column eight gives the percentage of manufacturing GDP that is attributable to the high energy-intensive industries as defined above. The energy-intensive segment of manufacturing declined (in relative terms) during most of the 1970s, made a small comeback in 1983, and has remained roughly constant since 1984.

Table 2 provides the year-by-year decomposition of the overall energy intensity for heat and power. Reductions in real energy intensity across the 75 sectors considered in the study were together responsible for a 4.35 reduction in energy intensity ( $\mathrm{kBtu} / 1987 \$)$ between 1972 and 1991 . The largest annual changes generally occurred in the immediate aftermath of the energy price shocks, first in 1974 and later in 1981. A large drop in intensities also occurred in 1978.

The data indicate that the overall change in industry-specific energy intensities has been negligible or perhaps even negative after 1987. Some of this decline may be attributable to a sluggish economy in 1990 and 1991 . Because of the fixed nature of some energy use, energy intensities will tend to increase during recessionary periods. Another factor may involve some amount of energy in the EIA industrial totals that is being used for electricity generation sold outside the industrial sector, thus overstating the increase in industrial consumption (see Reference 3). As discussed in the Appendix, the sum of individual industry consumption estimates is calibrated in each year to match the EIA control total. Although this factor may be biasing the most recent trend of intensities upward, it does not change the overall conclusion that intensities have moved little since 1985. 
Table 2. Decomposition of Change in Industrial Fuel Consumption for Heat and Power

\begin{tabular}{||r|r|r|r|r|r|r|r||}
\hline Year & $\begin{array}{c}\text { Energy } \\
\text { Intensity }\end{array}$ & $\begin{array}{c}\text { Within } \\
\text { 2-Digit (S5) }\end{array}$ & $\begin{array}{c}\text { Output } \\
\text { Definition (S4) }\end{array}$ & $\begin{array}{c}\text { 2-Digit } \\
\text { Shift (S3) }\end{array}$ & $\begin{array}{c}\text { Major Energy } \\
\text { Users (S2) }\end{array}$ & $\begin{array}{c}\text { Manufacl } \\
\text { Nonmanu. (S1) }\end{array}$ & $\begin{array}{c}\text { Total } \\
\text { Change }\end{array}$ \\
\hline 1972 & 0.00 & 0.00 & 0.00 & 0.00 & 0.00 & 0.00 & 0.00 \\
\hline 1973 & -0.31 & 0.03 & -0.63 & -0.18 & 0.32 & 0.33 & -0.45 \\
\hline 1974 & -1.89 & 0.21 & 0.38 & -0.12 & 0.43 & 0.28 & -0.70 \\
\hline 1975 & -1.28 & 0.04 & 0.14 & 0.11 & -0.36 & 0.18 & -1.17 \\
\hline 1976 & -1.59 & 0.02 & 0.08 & -0.12 & -0.17 & 0.38 & -1.40 \\
\hline 1977 & -2.29 & -0.07 & 0.22 & -0.23 & -0.34 & 0.49 & -2.22 \\
\hline 1978 & -3.13 & -0.15 & 0.94 & -0.64 & -0.55 & 0.55 & -2.96 \\
\hline 1979 & -2.91 & -0.11 & 1.57 & -0.59 & -0.79 & 0.62 & -2.20 \\
\hline 1980 & -2.96 & -0.16 & 2.13 & -0.74 & -1.45 & 0.50 & -2.67 \\
\hline 1981 & -3.70 & -0.22 & 0.80 & -0.18 & -1.09 & 0.62 & -3.76 \\
\hline 1982 & -3.63 & -0.41 & 0.61 & -0.42 & -1.59 & 0.59 & -4.86 \\
\hline 1983 & -4.56 & -0.49 & 0.49 & -0.51 & -1.41 & 0.66 & -5.84 \\
\hline 1984 & -4.14 & -0.46 & 0.52 & -0.49 & -1.81 & 0.60 & -5.79 \\
\hline 1985 & -4.38 & -0.62 & -0.01 & -0.49 & -1.93 & 0.49 & -6.94 \\
\hline 1986 & -4.90 & -0.71 & 0.10 & -0.93 & -1.61 & 0.50 & -7.56 \\
\hline 1987 & -5.14 & -0.63 & -0.08 & -0.70 & -1.65 & 0.58 & -7.63 \\
\hline 1988 & -5.01 & -0.55 & -0.23 & -0.44 & -1.86 & -0.63 & -7.46 \\
\hline 1989 & -4.73 & -0.55 & -0.16 & -0.66 & -1.89 & 0.68 & -7.32 \\
\hline 1990 & -4.45 & -0.56 & -0.23 & -0.79 & -1.75 & 0.61 & -7.17 \\
\hline 1991 & -4.35 & -0.64 & -0.24 & -0.69 & -1.69 & 0.63 & -6.98 \\
\hline
\end{tabular}

Consistent with the findings of Boyd et al., ${ }^{(2)}$ who used somewhat different data sources, the major shift component is the intergroup shift within manufacturing. The decline in GDP originating in the five energy-intensive two-digit SIC industries alone accounted for a reduction of $1.72 \mathrm{kBtu} / 1987 \$$ between 1972 and 1991 . Consistent with the behavior of the share in Table 1 (column eight), this factor, however, has remained fairly constant since 1984.

All of the other shift components also contributed to a decline in energy consumption over the study period, with the exception of the shift between manufacturing and nonmanufacturing. The manufacturing sector, which is more energy intensive per dollar of GDP than the remainder of the industrial sector, increased its share of total industrial GDP from 65 percent in 1972 to 70 percent in 1991.

\section{Results for Energy Used as Materials}

Column five in Table 1 shows the estimated amount of energy that is used as material inputs to production in the industrial sector. In 1991, the materials use of energy was about $18 \%$ of total (delivered) energy consumption. The adjoining column shows that aggregate energy materials intensity grew during the 1970s, fell sharply after the price shocks of 1979-1980, and has remained constant through the remainder of the 1980s.

Table 3 shows the year-by-year decomposition as applied to energy consumption for materials. As indicated above, column one shows that material intensities were most strongly affected by the price shock of 1979-1980 (in contrast, the behavior here reflects the decline of materials use in those industries that use energy for this purpose). Much of this decline is due to the reduction in petrochemical feedstocks per dollar of output in the basic chemical industries. The results also suggest a slowing or even reversal of this trend in the most recent years.

The effect of industrial output composition is somewhat more complex in explaining the movement in the overall energy materials intensity. As for heat and power, the shift to manufacturing in general tended to slightly increase 
Table 3. Decomposition of Change in Industrial Fuel Consumption for Materials

\begin{tabular}{||r|r|r|r|r|r|r|r||}
\hline Year & $\begin{array}{c}\text { Energy } \\
\text { Intensity }\end{array}$ & $\begin{array}{c}\text { Within } \\
\text { 2-Digit (S5) }\end{array}$ & $\begin{array}{c}\text { Output } \\
\text { Definition (S4) }\end{array}$ & $\begin{array}{c}\text { 2-Digit } \\
\text { Shift (S3) }\end{array}$ & $\begin{array}{c}\text { Major Energy } \\
\text { Users (S2) }\end{array}$ & $\begin{array}{c}\text { Manufacl } \\
\text { Nonmanu. (S1) }\end{array}$ & $\begin{array}{c}\text { Total } \\
\text { Change }\end{array}$ \\
\hline 1972 & 0.00 & 0.00 & 0.00 & 0.00 & 0.00 & 0.00 & 0.00 \\
\hline 1973 & 0.08 & 0.02 & -0.14 & -0.16 & 0.08 & 0.04 & 0.02 \\
\hline 1974 & 0.34 & -0.04 & 0.23 & -0.23 & 0.10 & 0.04 & 0.43 \\
\hline 1975 & 0.40 & -0.16 & -0.03 & 0.13 & -0.11 & 0.02 & 0.24 \\
\hline 1976 & 0.09 & -0.14 & -0.10 & 0.26 & -0.06 & 0.06 & 0.11 \\
\hline 1977 & -0.07 & -0.05 & -0.10 & 0.40 & -0.10 & 0.09 & 0.15 \\
\hline 1978 & -0.10 & -0.02 & 0.00 & 0.38 & -0.17 & 0.10 & 0.19 \\
\hline 1979 & 0.08 & -0.09 & 0.15 & 0.42 & -0.24 & 0.12 & 0.44 \\
\hline 1980 & 0.19 & -0.17 & 0.47 & 0.31 & -0.45 & 0.09 & 0.43 \\
\hline 1981 & -0.16 & -0.24 & 0.16 & 0.44 & -0.34 & 0.12 & -0.02 \\
\hline 1982 & -0.48 & -0.31 & -0.04 & 0.79 & -0.50 & 0.11 & -0.43 \\
\hline 1983 & -0.70 & -0.20 & -0.09 & 0.86 & -0.44 & 0.13 & -0.44 \\
\hline 1984 & -0.66 & -0.15 & 0.13 & 0.70 & -0.57 & 0.12 & -0.43 \\
\hline 1985 & -0.66 & -0.16 & -0.01 & 0.75 & -0.61 & 0.09 & -0.60 \\
\hline 1986 & -0.52 & -0.26 & -0.08 & 0.77 & -0.50 & 0.09 & -0.49 \\
\hline 1987 & -0.66 & -0.20 & -0.19 & 0.94 & -0.51 & 0.11 & -0.50 \\
\hline 1988 & -0.66 & -0.24 & -0.18 & 0.96 & -0.59 & 0.13 & -0.59 \\
\hline 1989 & -0.69 & -0.24 & -0.21 & 0.98 & -0.60 & -0.5 & -0.62 \\
\hline 1990 & -0.58 & -0.23 & -0.19 & 0.95 & -0.55 & 0.12 & -0.47 \\
\hline 1991 & -0.49 & -0.31 & -0.16 & 0.90 & -0.53 & 0.13 & -0.46 \\
\hline
\end{tabular}

the overall intensity. Again, a much stronger influence is attributed to a relative increase in GDP from the energy-intensive manufacturing industries, yielding a -0.54 reduction in the intensity by 1991 . In contrast, the component due to shifts within the two major manufacturing groups (S3 or "two-digit SIC" shift) worked against a decline in the overall materials intensity ( +0.90 by 1991$)$. The effect is likely due to the relative increase in chemicals within the energy-intensive manufacturing group. On balance, the effect of the various compositional shifts net to roughly zero over the entire period.

\section{SUMMARY AND CONCLUSIONS}

The analysis suggests that the pattern of energy conservation in the industrial sector-over time and by fuel-has been a complex one. Simple analysis of the energy-GDP ratio fails to deal with many underlying trends. Between 1972 and 1991, the decline in industrial sector delivered energy intensity contributed nearly one-third of the overall decline in energy-GDP ratio. The contribution from the industrial sector was greater than all of the other major end-use sectors combined. Much of the decline in the energy-GDP ratio stemming from structural factors is also due to the industrial sector, since industrial GDP has fallen relative to total GDP.

Between 1972 and 1991, changes in energy intensities at the individual industry level account for a reduction of $4.3 \mathrm{kBtu} / 1987 \$(20.3 \%)$ in the overall delivered energy intensity for the industrial sector. At the 1991 level of industrial GDP, this translates into about 5.7 QBtu of energy savings since 1972. Reductions in intensities for energy materials have contributed an additional 0.6 QBtu of savings.

The amalgam of structural effects was responsible for a drop of $2.62 \mathrm{kBtu} / 1987 \$(12.3 \%)$ in the overall energy intensity for industrial energy use for heat and power. Translated to energy savings for 1991, this factor contributed about 3.40 QBtu of energy savings in the total economy. The most important of these effects was the shift away from the major energy-intensive materials industries, but this factor has shown little change since the mid1980s. 
The aggregate data indicate that overall industrial intensity for heat and power has changed little since 1985. However, since 1987, the overall intensity has increased, primarily as a result of apparent increases in intensities at the industry specific level. These increases began before the mild recession of 1991 .

The short-term behavior of the industry-specific intensities should also be viewed in light of the use of the EIA industrial energy statistics as control totals in the data construction process. The classification of fuel use for electricity generation by large industrial facilities and other non-utility electricity producers may be beginning to distort the overall trends purported to show energy use for heat and power. The future challenge is to better reconcile the information on industrial fuel consumption between the establishment surveys (Manufacturing Energy Consumption Survey [MECS] ${ }^{(5)}$ and the Annual Survey of Manufactures) and the supplier information provided to EIA. This work is important in accurately assessing the most recent trends in industrial energy efficiency.

\section{APPENDIX: DATA SOURCES}

The overall data period for the complete decomposition analysis covered 1972 through 1991 . This period matches the one used in a recent comprehensive study by Pacific Northwest Laboratory of energy-use trends in the U.S. economy. ${ }^{(1)}$

A complete analysis requires a consistent set of outputs, energy consumption, and energy intensity. As discussed above, output data involve both gross production measures and GDP by industry data. The gross output measures are in constant 1987 dollars, as supplied by BLS' Office of Economic Growth. The 112 BLS sectors corresponding to the industrial sector for this study were aggregated to 75 sectors to better match the energy data from the National Energy Accounts. ${ }^{(6)}$

The National Energy Accounts (NEA) was prepared for the U.S. Department of Commerce by Jack Faucett Associates. The NEA contains annual time series of consumption for 35 energy products in 122 economic sectors for the period 1958-1985. The last formal update of the NEA included an integration of Annual Survey of Manufactures data and information from the first (1985) Manufacturing Energy Consumption Survey (MECS), conducted by the Energy Information Administration.

A significant portion of the effort for this study was devoted to extending the NEA through 1991 in sufficient depth to adequately characterize industrial sector energy use. A key problem is that after 1981, the Census Bureau no longer collected detailed quantity consumption for individual fuels as part of the Annual Survey of Manufactures (ASM). Instead, the only data on fuels in the ASM now relate to their total cost. The general procedure here was to develop industry-specific factors to extrapolate the 1985 NEA estimates for total fuels to 1991 . These factors were based on the percentage change in expenditures from the ASM, with an adjustment for changes in fuel prices.

A two-stage procedure was followed to generate industry-specific fuels deflators. In the first stage, a total fuels deflator for each sector for 1986-1991 (using 1985 as a base) was constructed by using the 1985 composition of expenditures, as estimated in the NEA, as a set of weights to apply to separate price indexes by fuel. Separate fuel price indexes were computed from the industrial fuel prices published in the State Energy Price and Expenditure Report 1991. ${ }^{(7)}$ In the second stage, these deflators were adjusted to match the percentage changes in fuel prices over time as estimated from the 1985, 1988, and 1991 MECS. The deflation procedure for fossil fuels preserves the basic data source from the ASM for the entire data period. 
The procedure above was used primarily because the MECS does not cover the industrial detail of the NEA and it uses a different industry sample than the ASM. Thus, it was not used in this study to develop fuel consumption estimates directly. The Census Bureau still collects the quantity of purchased electricity in the ASM; after aggregation, these data could be used directly for the period 1986-1991.

In agriculture, mining, and construction, the update through 1991 incorporated much, but not all, of the NEA estimation methodology, as documented by Jack Faucett Associates. Again, the overall approach was to develop a suitable extrapolator of the 1985 NEA figures. In agriculture, the extrapolators for total fuels and for electricity were based on deflated cost of production information published in Farm Production Expenditures. Extrapolators for mining and construction were based on data released as part of the 1987 Census reports.

Estimates for fuels used for materials were based to the largest extent possible on the methodology described in the 1989 update to the NEA. Unpublished data from the EIA were used to disaggregate the industrial consumption of "other" petroleum products. ("Other" petroleum consumption accounted for $3.3 \mathrm{QBtu}$, or 40 percent of industrial petroleum consumption..$^{(3)}$ ) This information on specific fuels was very helpful in providing control total for petrochemical feedstocks. Asphalt and lubricants are both published separately in the SEDR.

Because the overall study of end-use sector conservation trends was tied to the EIA measures of fuel consumption (from the SEDR), ${ }^{(3)}$ the resulting industrial estimates were finally scaled to match the industrial sector totals. Separate scaling was done for the heat and power versus materials usage components. At the aggregate level, this procedure facilitates the simple overall intensity metric of the SEDR-based energy use/industrial GDP. For heat and power, the scaling factors for 1972,1985 , and 1991 were $1.117,1.187$, and 1.189 , respectively. Thus, taking the final six years of the study period as a whole, the calibration procedure does not influence the effect of industry-specific intensity changes.

\section{REFERENCES}

1. Department of Energy: 1995. Energy Conservation Trends - Understanding the Factors Affecting Conservation Gains and their Implications for Policy Development. DOE/PO-0034, U.S. Department of Energy, Washington D.C.

2. G. Boyd, J.F. McDonald, M. Ross and D.A. Hanson. April 1987. "Separating the changing composition of US manufacturing production from energy efficiency improvements: A Divisia index approach." The Energy Journal.

3. Energy Information Administration. 1994. State Energy Data Report 1992. DOE/EIA-0214(92), U.S. Department of Energy, Washington D.C.

4. G. Boyd, D.A. Hanson and T. Sterner. October 1988. "Decomposition of changes in energy intensity: A comparison of the Divisia and other methods." Energy Economics.

5. Energy Information Administration. 1994. Manufacturing Consumption of Energy. DOE/EIA-0512(91), U.S. Department of Energy, Washington D.C.

6. Jack Faucett Associates. February 1989. National Energy Accounts, 1958-1985. Prepared for the U.S. Department of Commerce under Contract Number 50-SAEA-7-00015.

7. Energy Information Administration. 1993. State Energy Price and Expenditure Report 1991. DOE/EIA-0376(91) U.S. Department of Energy, Washington, D.C. 